\title{
Using seascape types to explain the spatial patterns of fish in the mangroves of SW Puerto Rico
}

\author{
Simon J. Pittman*, Chris Caldow, Sarah D. Hile, Mark E. Monaco \\ NOAA/NOS/CCMA Biogeography Team, 1305 East-West Highway, Silver Spring, Maryland 20910, USA
}

\begin{abstract}
Many of the most abundant fish species using mangroves in the Caribbean also use other habitat types through daily home range movements and ontogenetic habitat shifts. Few studies, however, have considered the structure of the surrounding seascape when explaining the spatial distribution of fish within mangroves. This study develops an exploratory seascape approach using the geographical location of mangroves and the structure of the surrounding seascape at multiple spatial scales to explain the spatial patterns in fish density and number of species observed within mangroves of SW Puerto Rico. Seascape structure immediately surrounding mangroves was most influential in determining assemblage attributes and the density of juvenile Haemulon flavolineatum, which were significantly higher in mangroves with high seagrass cover $(>40 \%)$ in close proximity $(<100 \mathrm{~m})$ than mangroves with low $(<40 \%)$ or no adjacent seagrasses. Highest mean density of juvenile Ocyurus chrysurus was found in offshore mangroves, with high seagrass and coral reef cover $(>40$ and $>15 \%$, respectively) in close proximity $(<100 \mathrm{~m})$. In contrast, juvenile Lutjanus griseus responded at much broader spatial scales, and with highest density found in extensive onshore mangroves with a large proportion ( $>40 \%$ ) of seagrass within $600 \mathrm{~m}$ of the mangrove edge. We argue that there is an urgent need to incorporate information on the influence of seascape structure into a wide range of marine resource management activities, such as the identification and evaluation of critical or essential fish habitat, the placement of marine protected areas and the design of habitat restoration projects.
\end{abstract}

KEY WORDS: Seascape structure - Mangroves · Seagrasses $\cdot$ Coral reef ecosystems $\cdot$ Spatial scale Fish · Puerto Rico · Caribbean

\section{INTRODUCTION}

Mangroves are generally considered to offer an important nursery function for many fish species and have been linked to highly productive coastal fisheries worldwide (Blaber 2000, Manson et al. 2005, Faunce \& Serafy 2006). It is now increasingly acknowledged, however, that mangroves may not always function in isolation to support fish populations (Sheaves 2005, Adams et al. 2006). In many regions, mangroves are connected to a mosaic of habitat types (e.g. seagrasses, coral reefs) through the movements of fish at a range of scales in time and space (Parrish 1989, Mumby et al. 2004, Pittman et al. 2004). In Caribbean mangroves, many of the most frequently observed fish species use multiple habitat types through daily home range movements (Rooker \& Dennis 1991, Nagelkerken et al. 2000, Verweij et al. 2006) and broader scale onshore-offshore ontogenetic habitat shifts (Cocheret de la Morinière 2002, Christensen et al. 2003, Mumby et al. 2004). As such, the nursery function of Caribbean mangroves may depend on spatial connectivity to other habitat types (Sheaves 2005); an attribute of the species-environment relationship, which is determined primarily by the interaction between animal mobility and the composition and spatial arrangement of resources across the seascape.

Nevertheless, a spatially explicit and quantitative consideration of the surrounding seascape structure is still a relatively novel approach in marine ecology. Concepts and analytical techniques developed in landscape ecology, however, provide an existing 
framework that can be readily applied to shallowwater marine systems (Robbins \& Bell 1994). Landscape ecology has been defined as the study of processes occurring across spatially heterogeneous mosaics and the biotic responses to the resultant patterns (Turner 1989). The underlying premise is that the composition and spatial arrangement of mosaic elements affect ecological processes in ways that would be different if the composition and arrangement were different (Dunning et al. 1992, Wiens et al. 1993). From an operational perspective, an exploratory seascape approach must quantify environmental variability at multiple spatial scales (Pittman \& McAlpine 2003, Pittman et al. 2004). A single-scale approach cannot incorporate important interactions occurring at other scales and is particularly inappropriate for studies of multi-species assemblages. Species, and even different life-stages of the same species, vary in their response to the environment due to functional differences in dietary requirements, habitat specialisations, body size and movements (Addicott et al. 1987, Wiens 1989, Wiens et al. 1993). Furthermore, comparing the strength of the species-environment association across scales allows determination of the scale exhibiting the strongest influence, typically referred to as the 'characteristic scale' (Holland et al. 2004).

The present study links daytime underwater fish census data collected within mangroves of the La Parguera Natural Wildlife Reserve (SW Puerto Rico) with geographical and seascape variables quantified within circles of different radii surrounding fish survey sites. We focus on the spatial patterns of density for 2 species of Haemulidae (Haemulon flavolineatum and $H$. sciurus) and 3 species of Lutjanidae (Lutjanus apodus, L. griseus and Ocyurus chrysurus), as well as the density and number of species of the fish assemblage observed within mangroves. We develop an exploratory approach (1) to identify the characteristic scale(s) of response to habitat by examining the strength of the correlation between the fish response variable and individual seascape variables across the scale range and (2) at these characteristic scales, we then examine the influence of multivariate seascape structure to identify the mangroves and associated seascape types that support the highest and lowest density of fish and number of fish species across the region.

\section{MATERIALS AND METHODS}

Study area. Fish censuses were conducted between 2001 and 2006 within mangroves of the La Parguera region of SW Puerto Rico (Fig. 1). The data was collected as part of a larger project designed to monitor and characterise fish-habitat relationships across Caribbean coral reef ecosystems (National Oceanic and Atmospheric Administration's Caribbean Coral Reef Ecosystem Monitoring Program).

The shoreline and islands of the area are lined with mangrove communities dominated by the red mangrove Rhizophora mangle. To the west, the onshore mangroves are extensive and extend to approximately $800 \mathrm{~m}$ from the land. To the east, there are less extensive fringing mangroves and many small mangrove islands. Adjacent sediments support seagrasses (dominated by Thalassia testudinum), macroalgae and unvegetated sand and sandy mud interspersed with coral reefs and patch reefs, which vary in patch size and benthic community composition. The tidal range is relatively small $(<0.5 \mathrm{~m})$, and mangrove prop roots at the seaward edge of the mangrove stands are continually immersed throughout the tidal cycle. For all mangroves sampled, mean water depth was $66 \mathrm{~cm}$ (range 30 to $152 \mathrm{~cm}$ ).

Sampling fish. A total of 145 spatially random mangrove survey sites were selected using a geographical information system (GIS) and a nearshore benthic habitat map for Puerto Rico (Kendall et al. 2002). Sampling was conducted in winter (January/February/ March) and fall (August/September/October) seasons each year, with approximately 10 to 12 spatially random sites selected across the study area for each field season. To quantify fish abundance, observers identified, counted and estimated the body lengths (fork length, FL) of all fish sighted within a $25 \mathrm{~m}$ long by $4 \mathrm{~m}$ wide belt transect $\left(100 \mathrm{~m}^{2}\right)$ using a standard daytime underwater visual census technique (adapted from Brock 1954). Transects were placed to directly follow the edge of the mangrove tree-line. Lengths were estimated in size-class ranges with $5 \mathrm{~cm}$ increments (i.e. $<5,5$ to 10,10 to $15 \mathrm{~cm}$ ). For individual species, only juveniles and sub-adults were included in the analysis and were distinguished based on lengths less than the mean length at maturity reported by García-Cagide et al. (1994).

Environmental data. Two types of spatial data were acquired: (1) geographical variables and (2) spatially explicit seascape variables. Geographical variables included distance to shore and the geographical location (latitude and longitude) of each fish transect extracted from the spatial data using a GIS. Seascape variables included the relative proportion of major habitat types (percent cover of mangroves, seagrasses, coral reefs and unvegetated sediments), the number of habitat types (habitat richness) and mean water depth quantified within circles of different radii $(50,100,200$, $300,400,500$ and $600 \mathrm{~m}$ ) surrounding each fish transect. Each circle surrounding a fish transect is referred to here as a seascape sample unit. The proportion and 


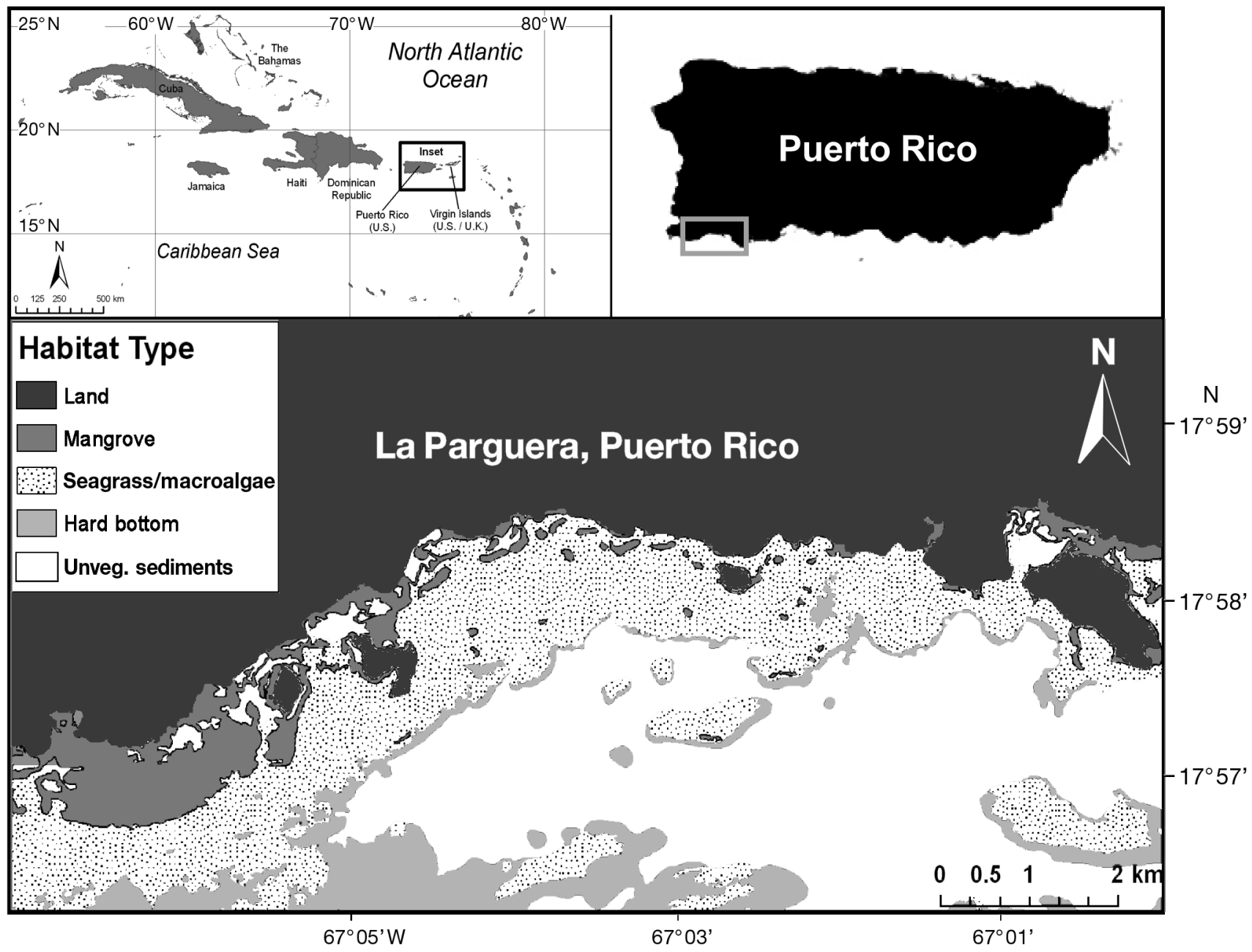

Fig. 1. Location of the study area in SW Puerto Rico. Map showing the 4 major habitat types included in this study as delineated in the NOAA's benthic habitat map

richness of habitat types were extracted from the nearshore benthic habitat map for Puerto Rico. To capture the full range of heterogeneity represented in the map, habitat richness was calculated as the total number of habitat classes within a seascape sample unit from all available classes at the level of 'habitat type' (maximum 13 habitat classes). Mean water depth in the surrounding seascapes was quantified from a bathymetric model developed using a triangulated interpolated network (TIN) on depth soundings data (National Geophysical Data Center) and supplemented by data from SCUBA divers. Vertical accuracy of the TIN model was validated (mean vertical error $<0.3 \mathrm{~m}$ ) using an independent set of bathymetric data. The TIN model was then converted into a raster map (5 $\times 5 \mathrm{~m}$ spatial resolution).

Scale selection. The range of radii for seascape sample units selected includes both sub-home range and supra-home range spatial scales for juvenile Haemuli- dae and Lutjanidae. Information on the scale of movement was based on the average maximum distance travelled for multiple individuals of each species using existing data from acoustic tracking and mark/recapture studies for durations ranging from hours to months (Table 1). The maximum distance travelled during routine daily movements is considered an appropriate measure for scaling ecologically relevant environmental patterns (Addicott et al. 1987). In the present study, a maximum radius of $600 \mathrm{~m}$ was selected to minimise overlap among sample units.

Statistical analyses. To examine the strength and directionality of the fish response to the individual seascape variables, and to determine the characteristic scale, we calculated the Spearman rank correlation coefficient $(\mathrm{rho}=r$ ) between all response variables and all seascape variables at each spatial scale. We tested for significance of the observed $r$ by comparing it with a simulated distribution of $r$ from re-sampled data 
Table 1. Approximate scale of movements for haemulids and lutjanids from a range of studies using mark/recapture and acoustic tracking

\begin{tabular}{|c|c|c|c|c|c|c|}
\hline Species & Life stage & $\begin{array}{l}\text { No. } \\
\text { of fish }\end{array}$ & $\begin{array}{l}\text { Mean (SD) } \\
\text { duration (d) }\end{array}$ & $\begin{array}{l}\text { Mean }(\mathrm{SD}) \max . \\
\text { distance }(\mathrm{m})\end{array}$ & Location & Source \\
\hline \multicolumn{7}{|l|}{ Haemulidae } \\
\hline Haemulon flavolineatum & Juvenile & 25 & $90.7(30.9)$ & $105.3(66.8)$ & Puerto Rico & Bouwmeester (2005) \\
\hline H. flavolineatum & Sub-adult & 28 & $198.6(129.6)$ & $93.6(68.1)$ & Puerto Rico & Bouwmeester (2005) \\
\hline H. sciurus & Sub-adult/adult & 10 & $11.3(9.3)$ & $279.2(227.9)$ & St. John, USVI & Beets et al. (2003) \\
\hline \multicolumn{7}{|l|}{ Lutjanidae } \\
\hline Lutjanus griseus & Juvenile/sub-adult & 10 & $64.3(0.48)$ & 648 (1216) & Florida & www.adoptafish.net \\
\hline
\end{tabular}

using 1000 random permutations. The spatial scale with the greatest proportion of maximum $r$ across all predictor variables was selected as the characteristic scale for each species/assemblage attribute. Following Holland et al. (2004), we took the scale of maximum correlation to be the scale of maximum response. In addition, the presence of spatial dependence in the response variables was tested using the global Moran's I statistic (Moran 1950).

To examine the association between multivariate seascape structure and the spatial patterns of fish density and number of species, we first defined seascape structural types at characteristic scales using hierarchical cluster analysis with complete linkage applied to a Bray-Curtis sample dissimilarity matrix (Primer v5 software, Plymouth Marine Laboratory). Bray-Curtis dissimilarities were calculated on the untransformed proportion of each habitat type (mangroves, seagrasses, coral reefs and unvegetated sediments) in the seascapes surrounding all mangrove sample sites. This technique partitioned the multiple gradients of habitat abundance across the study area into distinct structural types that were then represented on a dendrogram. Similarity percentages (SIMPER) analysis was used to identify the seascape variables that contributed most to the dissimilarity between groups (Clarke \& Warwick 1994).

Non-metric multidimensional scaling (nMDS) plots were used to (1) delineate the seascape structural types in ordination space and (2) display overlays of fish density and number of species by sample site. Sites in close proximity to one another in the ordination space are the most similar in structure, whereas sites that plot farther away from each other are less similar (Clarke \& Warwick 1994). The goodness-of-fit of the ordination is ranked by the stress index, which measures how well a particular plot of similarities corresponds to the observed distance matrix. Stress values range from 0 to 1 , where low values $(<0.05)$ indicate a good fit and high values $(>0.2)$ indicate a poor fit (Kruskal 1964). The nonparametric Kruskal-Wallis 1-way analysis of variance test, followed by Dunn's multiple pairwise comparison test, was used to examine differences in the fish response among seascape structural types.

\section{RESULTS}

Within the mangroves of SW Puerto Rico 176188 individual fish of 96 species from 32 families were observed. The most frequently occurring fish species were Lutjanus apodus (100\% of samples), Stegastes leucostictus (76\%), Haemulon sciurus (77\%), H. flavolineatum (77\%), Sphyraena barracuda (65\%), Abudefduf saxatilis (59\%) and Chaetodon capistratus (58\%). Lutjanus griseus and Ocyurus chrysurus were observed in 46 and $12 \%$ of samples, respectively.

\section{Spatial autocorrelation}

The response data were not significantly spatially autocorrelated (Moran's $I=-0.49$ to 0.14 , p > 0.1) and therefore the geographical distribution of samples was not considered to have biased correlation coefficients calculated to determine the characteristic scales.

\section{Determining a characteristic scale of response}

For density and number of species of assemblages, and for density of Haemulon flavolineatum and Ocyurus chrysurus, correlation coefficients were highest at the $100 \mathrm{~m}$ radius scale for 3 or more of the 6 seascape variables, and thus the $100 \mathrm{~m}$ radius scale was considered the characteristic scale for subsequent analysis (Table 2). In contrast, Lutjanus griseus density was most strongly correlated at the $600 \mathrm{~m}$ scale for 4 out of 6 seascape variables, and thus the $600 \mathrm{~m}$ radius scale was considered the characteristic scale for subsequent analysis (Table 2). More ambiguous was Haemulon sciurus, which showed significant correlations at the $600 \mathrm{~m}$ (seagrass cover) and $200 \mathrm{~m}$ scales (unvege- 
Table 2. Characteristic scales (bold) for the fish response to seascape variables and the associated maximum correlation coefficient (in parentheses). All correlation coefficients are statistically significant $(\mathrm{p}<0.05)$. n.s.: not significant

\begin{tabular}{|c|c|c|c|c|c|c|}
\hline \multirow[t]{2}{*}{ Response } & \multirow[b]{2}{*}{ Mangrove } & \multirow[b]{2}{*}{ Seagrass } & \multicolumn{2}{|c|}{ - Seascape variable } & \multirow[b]{2}{*}{$\begin{array}{l}\text { Habitat } \\
\text { richness }\end{array}$} & \multirow[b]{2}{*}{$\begin{array}{c}\text { Mean water } \\
\text { depth }\end{array}$} \\
\hline & & & Coral reef & Unvegetated & & \\
\hline \multicolumn{7}{|l|}{ Assemblage } \\
\hline Density & $100(-0.31)$ & $100(0.33)$ & $100(0.16)$ & $100(-0.31)$ & $\mathbf{6 0 0}(0.31)$ & $\mathbf{3 0 0}(0.31)$ \\
\hline Number of species & $100(-0.23)$ & $500(0.33)$ & $\mathbf{5 0}(-0.14)$ & $100(-0.22)$ & $100(-0.17)$ & $200(-0.16)$ \\
\hline \multicolumn{7}{|l|}{ Haemulidae } \\
\hline Haemulon flavolineatum & $100(-0.27)$ & $100(0.33)$ & n.s. & $100(-0.21)$ & $\mathbf{5 0 0}(0.16)$ & $\mathbf{3 0 0}(0.25)$ \\
\hline H. sciurus & n.s. & $600(0.25)$ & n.s. & $200(-0.26)$ & $50(-0.16)$ & n.s. \\
\hline \multicolumn{7}{|l|}{ Lutjanidae } \\
\hline Ocyurus chrysurus & $100(-0.22)$ & $100(0.18)$ & $100(0.12)$ & $\mathbf{5 0 0}(0.14)$ & $50(-0.11)$ & $300(0.19)$ \\
\hline Lutjanus griseus & $600(0.43)$ & $100(-0.34)$ & $\mathbf{5 0 0}(-0.45)$ & $600(-0.21)$ & $600(-0.38)$ & $600(-0.44)$ \\
\hline L. apodus & n.s. & n.s. & n.s. & n.s. & n.s. & n.s. \\
\hline
\end{tabular}

tated cover), but with strongest correlation at the $600 \mathrm{~m}$ scale (Table 2).

\section{Defining seascape structural types}

At both the 100 and $600 \mathrm{~m}$ spatial scales, cluster analysis identified 7 groupings of samples that were $>35 \%$ dissimilar to each other, of which the largest 6 groups were labelled Seascape Types A, B, C, D, E \& F. The groups were easily delineated on nMDS ordination plots, with low stress values of 0.05 (100 m seascapes) and 0.09 (600 m seascapes), indicating 'excellent' and 'good' 2-dimensional representation of the data structure, respectively (Fig. 2). Mean ( \pm SD) dissimilarity was $54 \pm 10.2 \%$ for all pairs of $100 \mathrm{~m}$ seascape types and $50 \pm 12.1 \%$ for $600 \mathrm{~m}$ seascape types.

\section{$100 \mathrm{~m}$ radius seascape types}

To improve interpretation, the six $100 \mathrm{~m}$ seascape types were further grouped into 2 highly dissimilar groups based on seascape characteristics. This division was delineated on the ordination with a broken line (Fig. 2). Highest pairwise percentage dissimilarity for $100 \mathrm{~m}$ seascapes was between 100A \& F (76\%), 100B \& $\mathrm{F}(67 \%), 100 \mathrm{C} \& \mathrm{~F}(63 \%)$ and $100 \mathrm{~A} \& \mathrm{E}(65 \%)$. Seascape Structural Types 100E \& F were the least structurally heterogeneous $100 \mathrm{~m}$ radius seascapes, composed of onshore mangroves (<800 m from shore), surrounded by relatively shallow water $(<2 \mathrm{~m})$, with low seagrass cover $(<40 \%)$ and no coral reefs in close proximity. The most structurally heterogeneous $100 \mathrm{~m}$ radius seascapes were $100 \mathrm{~A} \& \mathrm{~B}$, composed of offshore (>800 $\mathrm{m}$ from shore) mangrove islands, with high seagrass cover $(>40 \%)$ in close proximity. In addition, Seascape Type 100A had the largest proportion of coral reefs (>15\%), and Seascape Type 100B had the deepest adjacent waters and the largest proportion of seagrass cover (>70\%). Seascape Types 100C \& D were mostly onshore mangroves, with very similar structural characteristics, but 100C mangroves had higher adjacent seagrass cover (mean of 64 versus $50.6 \%$ ) (Table 3 ). Mean pairwise similarity percentages determined that distance to shore $(39 \pm 5.6 \%)$ and the proportion of mangroves $(25 \pm 5.8 \%)$ and unvegetated cover $(22 \pm$ $8.4 \%$ ) in the seascape contributed most to the differences between Seascape Types 100A, B \& C and 100E \& F (Table 3).

\section{$600 \mathrm{~m}$ radius seascape types}

The six $600 \mathrm{~m}$ radius seascape types were divided into 3 types with maximum dissimilarity and delineated with a broken line on the ordination (Fig. 2). Highest pairwise dissimilarity was calculated for 600A \& E (62\%), 600A \& C (57\%), 600A \& B (53\%), 600B \& D $(54 \%)$ and $600 B$ \& C (47\%). Seascape Structural Types $600 \mathrm{~A} \& \mathrm{~F}$ were the least heterogeneous $600 \mathrm{~m}$ radius seascapes, composed of onshore mangroves $(<800 \mathrm{~m}$ from shore), with low to medium seagrass and mangrove cover $(<40 \%)$ and very low $(<5 \%)$ or no coral reefs (Table 3 ). Types 600D \& $\mathrm{C}$ were considered the most highly heterogeneous of the onshore seascapes, with higher seagrass cover ( $>40 \%)$, low unvegetated cover $(<25 \%)$, low coral reef cover $(<8 \%)$ and medium habitat richness (4 to 8 classes). Types 600B \& E were the most highly heterogeneous seascapes, composed of relatively small offshore mangrove islands, surrounded by deeper water ( $>15 \mathrm{~m}$ mean water depth), with the largest proportion of coral reefs $(>10 \%)$, low-medium seagrass cover $(>30 \%)$, relatively high unvegetated cover ( $>20 \%$ ) and habitat richness (6 to 13 ). Mean pairwise similarity percentages determined that distance to 
shore $(42 \pm 4.1 \%)$ and the proportion of seagrasses in the seascape $(27 \pm 8.2 \%)$ contributed most to the differences between all 3 groups of seascape types.

\section{Linking fish density and number of species to seascape types}

\section{Assemblages}

Fish assemblage density within mangroves was significantly higher (Kruskal-Wallis, $K=22.6$, p < $0.001)$ in seascapes with high seagrass cover $(>40 \%)$ in
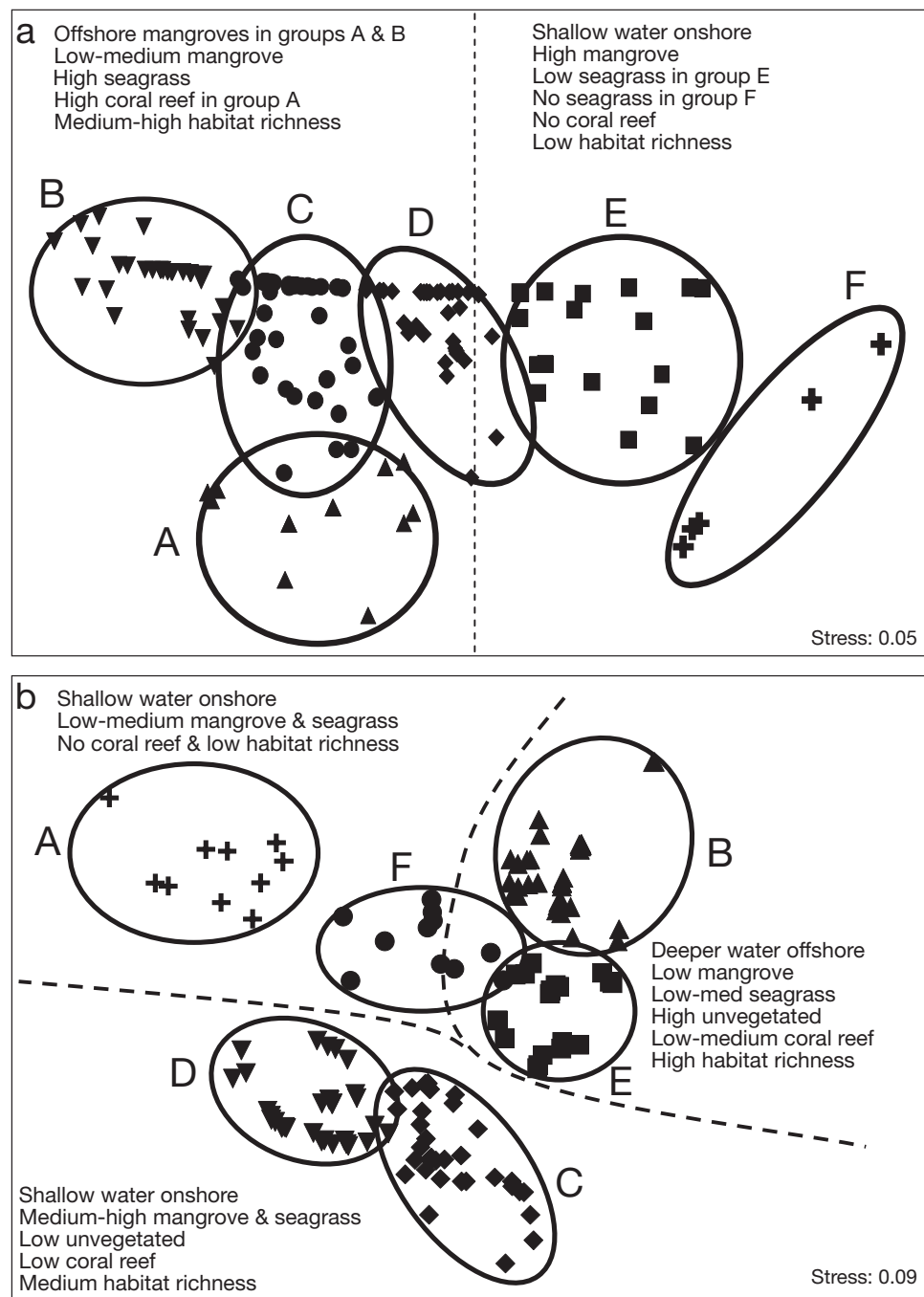

Fig. 2. Structural dissimilarity amongst (a) $100 \mathrm{~m}$ seascape structural types and (b) $600 \mathrm{~m}$ seascape structural types using non-metric multidimensional scaling plots (nMDS) showing the relative dissimilarity in seascape composition (percent cover of seagrasses, mangroves, coral reefs and unvegetated sediments) for all samples. Seascape structural types are encircled and labelled (A, B, C, D, E \& F) according to cluster groups identified using a hierarchical cluster analysis. The groups of seascapes with highest structural dissimilarity are separated with broken lines close proximity $(<100 \mathrm{~m})$. This was demonstrated by significantly higher fish densities in mangroves of Seascape Types 100A, B, C \& D when compared to Seascape Types 100E \& F (Fig. 3). Overall, highest mean assemblage density was recorded for the most structurally heterogeneous seascape types (100B \& A), composed of offshore mangroves, with high seagrass cover and with close proximity to coral reefs and deeper water areas. Lowest mean density was recorded for the least heterogeneous seascapes (100E $\&$ F), composed of onshore mangroves, with little or no seagrass cover or coral reefs in close proximity. Mean number of species was also higher in the more structurally heterogeneous seascape types, but significant differences were only detected between Seascape Types 100B and 100E \& F (Kruskal-Wallis, $K=17.7$, p $<0.001$ ). Highest mean number of species was reported for the 100B seascapes, characterised as offshore mangroves with deeper adjacent water and the highest seagrass cover (Fig. 3).

Haemulidae

Haemulon flavolineatum were observed using mangroves in all seascape structural types, but with markedly higher mean densities found within mangroves of seascape types with high adjacent seagrass cover (Fig. 4). Significantly higher mean density was recorded for the 100B seascape type when compared with the lowest mean density recorded for $100 \mathrm{E} \& \mathrm{~F}$ seascapes (Kruskal-Wallis, $K=13.5 \mathrm{p}<0.05$ ). In fact, $H$. flavolineatum was only recorded in 1 sample from Seascape Type 100F. Haemulon sciurus were widely distributed amongst mangroves across the region, with a relatively high mean density recorded in both offshore (600B \& E) and onshore mangroves (600C \& D) with adjacent seagrasses (Fig. 5). Lowest mean density was found in mangroves (600A $\&$ F) that were closest to shore, with no coral reefs within $600 \mathrm{~m}$ (Kruskal-Wallis, $K=11.2$, $\mathrm{p}<0.05)$.

\section{Lutjanidae}

Ocyurus chrysurus were absent from onshore mangroves in Seascape Type 100F, and only 1 individual was sighted from the 17 samples in 100E seascapes (Fig. 4). Highest mean density was reported from the 
Table 3. Characterisation of 100 and $600 \mathrm{~m}$ seascape structural types using mean $( \pm$ SE) value for environmental variables from samples grouped by cluster grouping

\begin{tabular}{|c|c|c|c|c|c|c|}
\hline \multirow{2}{*}{ Habitat variable } & \multicolumn{6}{|c|}{ - Seascape type } \\
\hline & A & B & $\mathrm{C}$ & $\mathrm{D}$ & $\mathrm{E}$ & $\mathrm{F}$ \\
\hline \multicolumn{7}{|l|}{$100 \mathrm{~m}$ radius spatial extent } \\
\hline Mangrove (\%) & $22.6(1.3)$ & $14.2(0.7)$ & $24.7(1.1)$ & $42.3(0.9)$ & $57.2(2.1)$ & $56(10.6)$ \\
\hline Seagrass $(\%)$ & $52.3(2.8)$ & $85.5(1.5)$ & $64(1.6)$ & $50.6(1.2)$ & $29.8(2.5)$ & $<1(<0.1)$ \\
\hline Coral reef (\%) & $27.4(1.6)$ & $2.1(0.6)$ & $1.4(0.5)$ & $0.5(0.3)$ & 0 & 0 \\
\hline Unvegetated (\%) & $0.3(0.3)$ & $0.1(<0.1)$ & $1.7(1.1)$ & $6(1.7)$ & $6.9(2.7)$ & $39.8(9.4)$ \\
\hline Number of habitat types & $4.2(0.1)$ & $2.9(0.1)$ & $3.1(0.1)$ & $2.7(0.1)$ & $2.9(0.2)$ & $2.4(0.2)$ \\
\hline Mean depth $(\mathrm{m})$ & $1.6(0.1)$ & $4.5(0.5)$ & $4.1(0.5)$ & $2.4(0.2)$ & $1.4(0.1)$ & $1.4(0.2)$ \\
\hline Distance to shore (km) & $1.2(0.1)$ & $0.9(0.1)$ & $0.4(0.1)$ & $0.3(<0.1)$ & $0.3(<0.1)$ & $0.2(0.01)$ \\
\hline \multicolumn{7}{|l|}{$600 \mathrm{~m}$ radius spatial extent } \\
\hline Mangrove (\%) & $21.5(1.4)$ & $3.7(0.4)$ & $8.3(0.6)$ & $32.7(1.9)$ & $2.9(0.4)$ & $8.3(1.5)$ \\
\hline Seagrass (\%) & $15.9(1.5)$ & $26.2(0.6)$ & $66.8(2.2)$ & $53.4(1.2)$ & $42.8(1.2)$ & $32.5(0.8)$ \\
\hline Coral reef (\%) & 0 & $14.1(0.8)$ & $2.1(0.5)$ & $0.26(0.1)$ & $15.2(1.2)$ & $1.2(0.7)$ \\
\hline Unvegetated (\%) & $24.9(3.4)$ & $49.1(2.7)$ & $6.6(0.6)$ & $5.91(0.8)$ & $32.5(2.2)$ & $25.9(5.2)$ \\
\hline Number of habitat types & $4.10(0.2)$ & $8.1(0.3)$ & $5.9(0.2)$ & $5.8(0.2)$ & $8.3(0.4)$ & $5.4(0.6)$ \\
\hline Mean depth $(\mathrm{m})$ & $4.7(0.6)$ & $27.2(1.7)$ & $13.1(0.6)$ & $5.0(0.3)$ & $21.6(1.0)$ & $14.5(2.1)$ \\
\hline Distance to shore $(\mathrm{km})$ & $0.15(<0.1)$ & $0.9(0.03)$ & $0.3(<0.1)$ & $0.47(<0.1)$ & $0.7(0.1)$ & $0.06(<0.1)$ \\
\hline
\end{tabular}
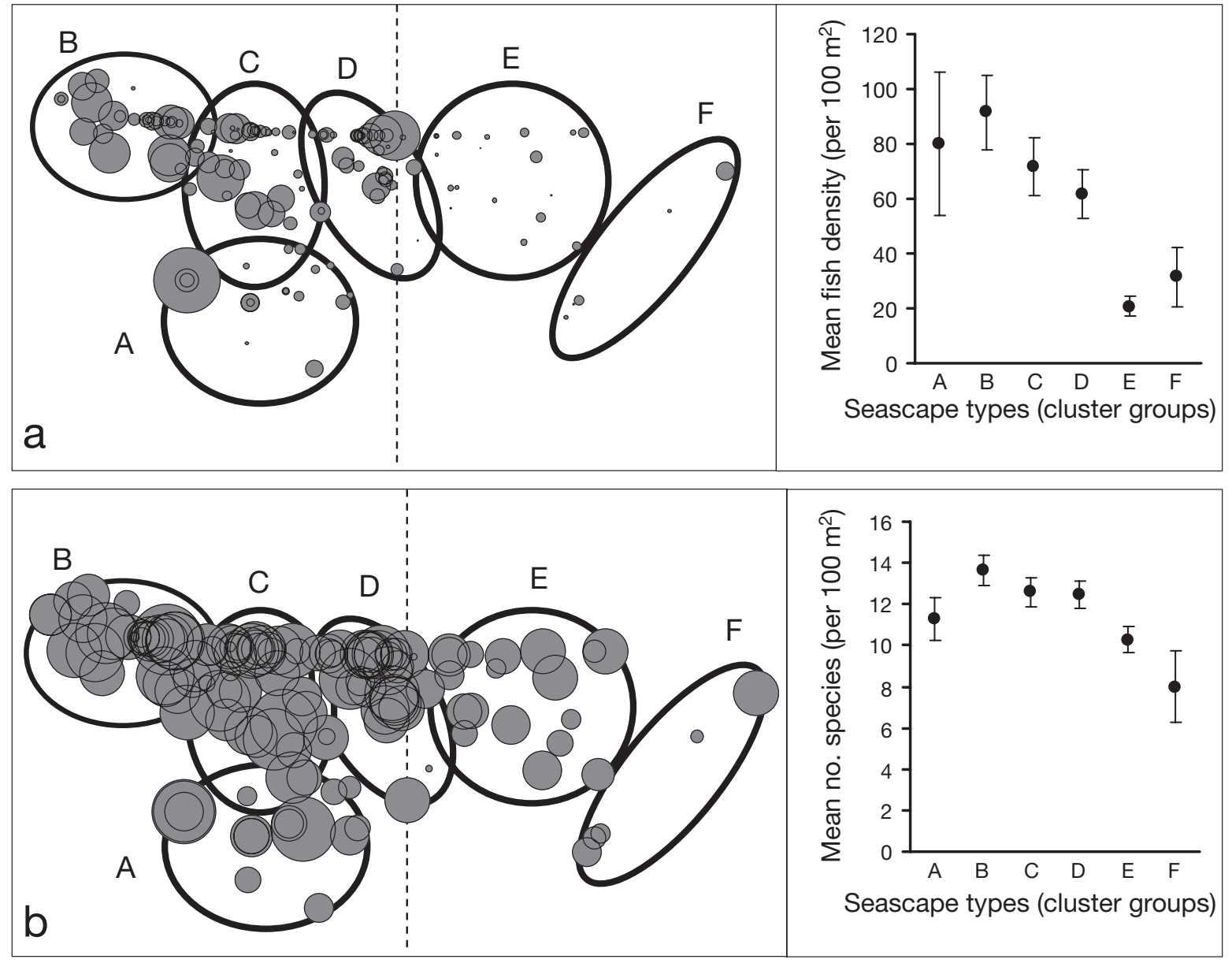

Fig. 3. Distribution of (a) fish assemblage density and (b) number of fish species within mangroves overlaid on an nMDS ordination of seascape structural dissimilarity at the $100 \mathrm{~m}$ radius scale. Grey circles are proportional in size to the value of density or number of fish species observed at each survey site. Seascape structural types are encircled and labelled (A, B, C, D, E \& F) according to cluster groups identified using a hierarchical cluster analysis. The accompanying charts show mean ( \pm SE) of (a) fish assemblage density and (b) number of species for each seascape type 

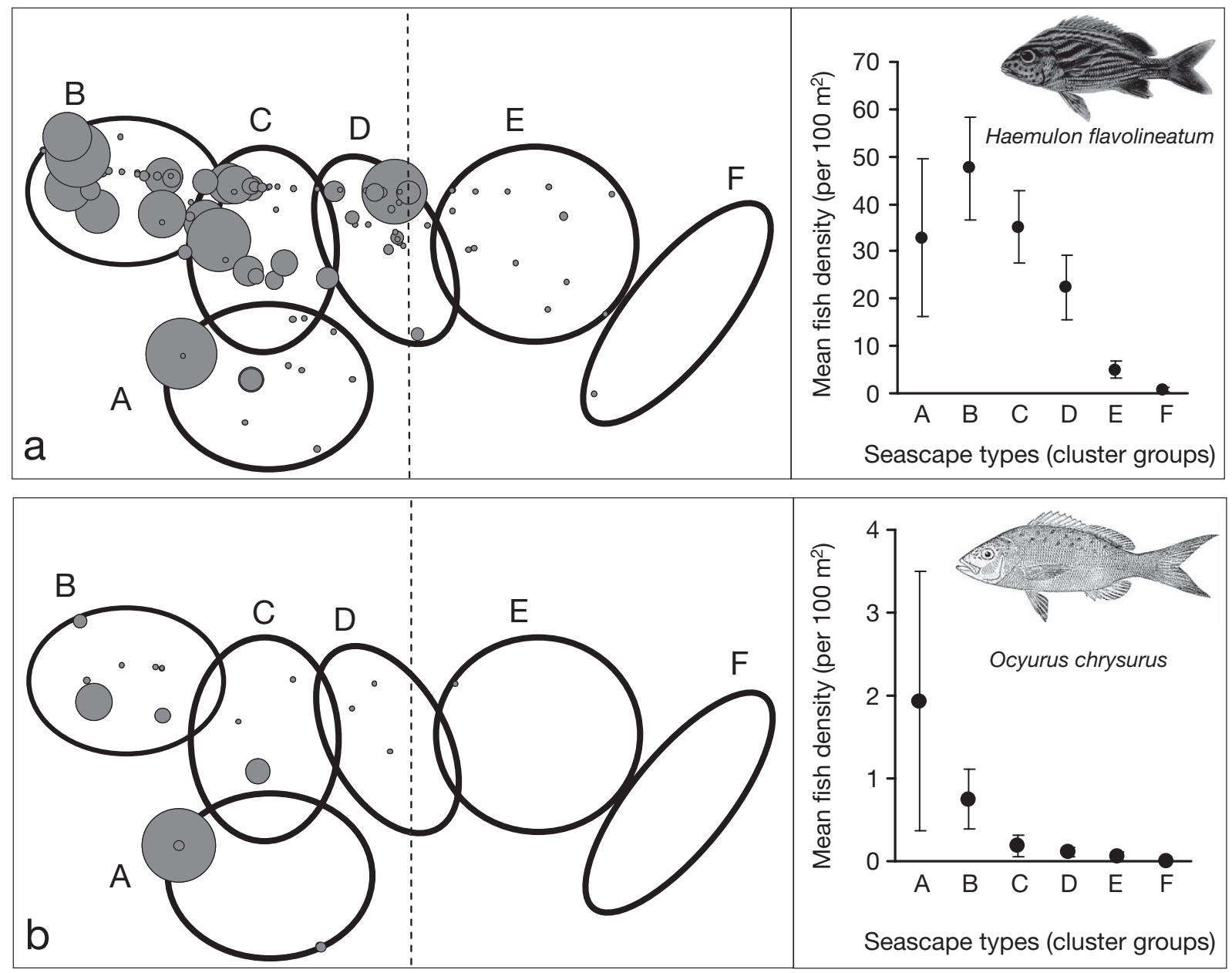

Fig. 4. Distribution of (a) Haemulon flavolineatum density and (b) Ocyurus chrysurus density within mangroves overlaid on an nMDS ordination of seascape structural dissimilarity at the $100 \mathrm{~m}$ radius scale. Grey circles are proportional in size to the value of density observed at each survey site. Seascape structural types are encircled and labelled (A, B, C, D, E \& F) according to cluster groups identified using a hierarchical cluster analysis. The accompanying charts show mean ( \pm SE) of (a) $H$. flavolineatum density and (b) O. chrysurus density for each seascape type. Fish illustrations provided courtesy of Bohlke \& Chaplin (1993)

mangrove islands (100A \& B) farthest offshore, with high seagrass cover and close proximity to high coral reef cover. In fact, Seascape Types 100A \& B accounted for $71 \%$ of the $O$. chrysurus sighted within mangroves of the study area. Mean density followed a similar pattern to Haemulon flavolineatum, but no significant differences (Kruskal-Wallis, $K=6.9$, p > 0.05) were detected for density of $O$. chrysurus between seascape structural types. Lutjanus griseus were observed using mangroves in all seascape types, with highest mean density in the most heterogeneous of the shallow onshore mangroves of 600C (Fig. 5). In contrast to the other species studied here, significantly lower mean density of $L$. griseus was recorded for offshore mangroves 600B \& E (Kruskal-Wallis, $K=29.2, \mathrm{p}<0.001$ ). L. apodus was not significantly correlated with any seascape variables.

\section{DISCUSSION}

In the present study, we developed a multi-scale seascape approach to explain spatial patterns in fish density and number of species. Our study revealed considerable spatial complexity in the densities of fish throughout the mangroves of SW Puerto Rico, which could not be explained adequately by any single environmental variable alone. We found that an understanding of the distribution patterns of fish with spatially complex life cycles and multi-habitat homerange movements necessitates consideration of both the geographical location of the mangrove and the structure of the surrounding seascape, particularly the amount of seagrasses. Furthermore, it appears that quality and suitability of a particular seascape type is species specific and likely determined by the biologi- 

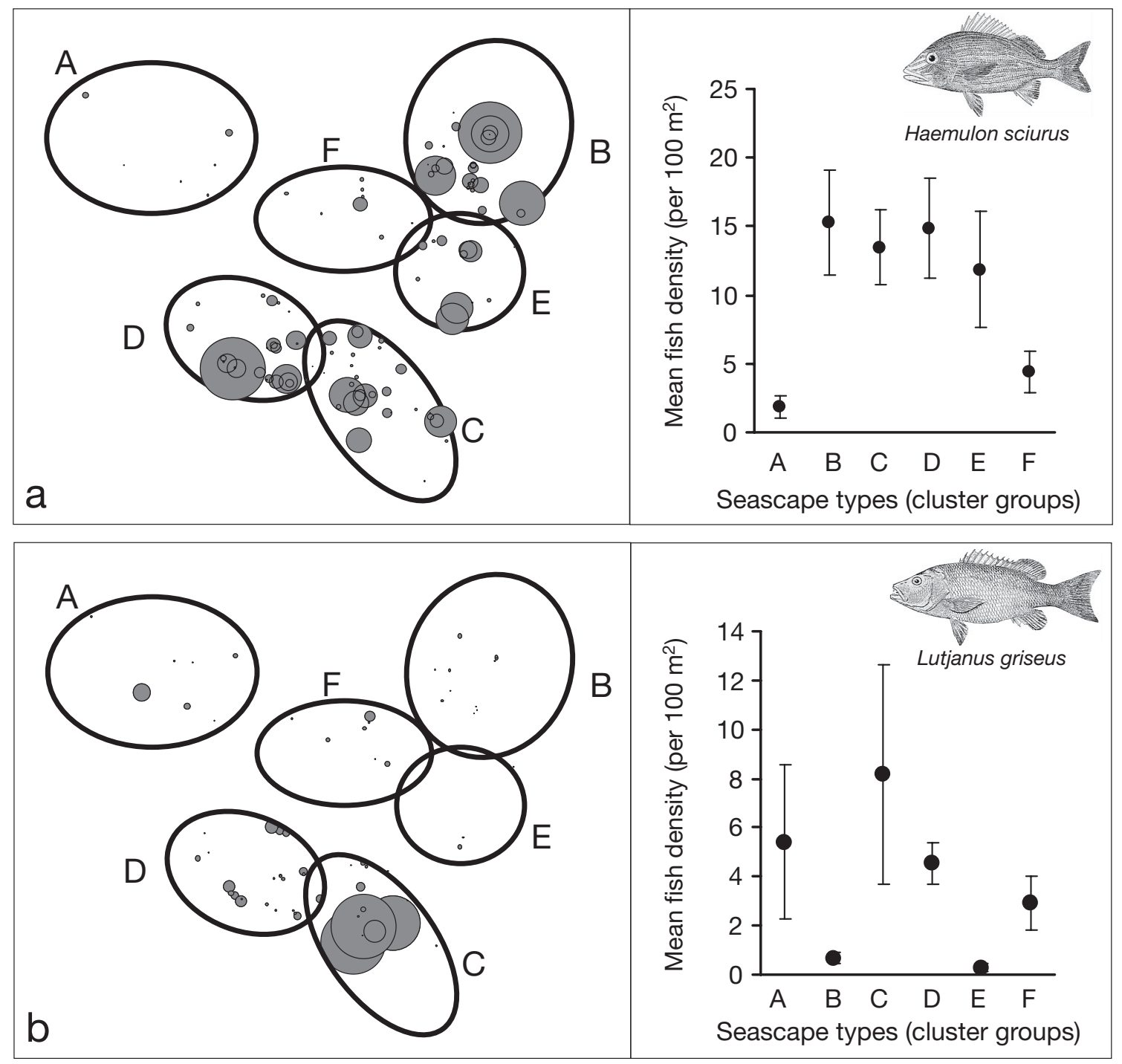

Fig. 5. Distribution of (a) Haemulon sciurus density and (b) Lutjanus griseus density within mangroves overlaid on an nMDS ordination of seascape structural dissimilarity at the $600 \mathrm{~m}$ radius scale. Grey circles are proportional in size to the value of density observed at each survey site. Seascape structural types are encircled and labelled (A, B, C, D, E \& F) according to cluster groups identified using a hierarchical cluster analysis. The accompanying charts show mean and standard error of (a) $H$. sciurus density and (b) L. griseus density for each seascape type. Fish illustrations provided courtesy of Bohlke \& Chaplin (1993)

cal characteristics of a species (e.g. mobility, lifehistory strategy and resource requirements).

\section{Determining a characteristic scale of response}

Our multi-scale approach allowed us to identify the scale(s) at which seascape structure had the most influence on fish. Fish that were likely to have exhibited relatively fine-scale movements responded more strongly to seascape structure immediately surrounding mangroves. In contrast, juveniles of fish capable of broader scale movements were found to respond more strongly to seascape structure at broader spatial scales. Overall, we found that the strongest bivariate correlations more frequently occurred at the $100 \mathrm{~m}$ radius spatial scale for fish assemblage density and number of species, as well as for density of Haemulon flavolineatum and Ocyurus chrysurus. In contrast, Lutjanus griseus and Haemulon sciurus appeared to respond to seascape structure at markedly broader spatial scales, suggesting that selection of a single scale for multi-species studies may be inappropriate and that characteristic scales may vary markedly between species even within a family.

Our results show good agreement between the characteristic scale selected for each species and the 
known spatial extent of fish movements estimated by fish tracking and tagging studies. For example, mark/ recapture experiments on juvenile and sub-adult Haemulon flavolineatum in SW Puerto Rico revealed a mean maximum distance moved of $105.3 \mathrm{~m}$ for 25 small juveniles ( 7.6 to $12.1 \mathrm{~cm} \mathrm{FL)} \mathrm{and} 93.6 \mathrm{~m}$ for 28 larger juveniles (10.9 to $14.9 \mathrm{~cm}$ FL) (Bouwmeester 2005). In addition, underwater observations of $H$. flavolineatum at St. Croix have shown that schools of juvenile grunts will move distances of 100 to $300 \mathrm{~m}$ to feed at night in seagrass beds (Ogden \& Ehrlich 1977). Juvenile Ocyurus chrysurus is also thought to exhibit relatively high site fidelity. Watson et al. (2002) carried out daytime observations of newly settled O. chrysurus $(<7 \mathrm{~cm} \mathrm{FL})$ in seagrass beds of the British Virgin Islands, with mean home ranges of $<35 \mathrm{~m}^{2}$. Furthermore, Lindholm et al. (2005) reported high site fidelity for 9 sub-adult $O$. chrysurus ( 21.5 to $26.5 \mathrm{~cm} \mathrm{FL}$ ) in the Florida Keys, with the majority of acoustic detections occurring at a single reef.

For Haemulon sciurus juveniles, our analysis found a stronger response at broader spatial scales than for H. flavolineatum, indicating that the characteristic scale may vary between species within a family. Interestingly, acoustic tracking of $H$. sciurus in St. John, US Virgin Islands, showed that fish were moving greater distances (mean 279 m, max. $767 \mathrm{~m}$ ) than has been shown for similar-sized $H$. flavolineatum (Beets et al. 2003). Support for the broader scale response of Lutjanus griseus also comes from acoustic tracking in Florida, with a mean maximum distance travelled of $648 \mathrm{~m}$, with the smallest juveniles showing relatively high site fidelity and larger juveniles making extensive movements (S. Whitcraft unpubl. data). Unfortunately, insufficient data is available on juvenile Lutjanus apodus to determine relevant spatial scales. In our study, L. apodus did not respond significantly to individual seascape variables at any scale, and additional analysis revealed that densities of juveniles were not significantly different between seascape structural types. This indicates that either L. apodus does not respond to the structure of the surrounding seascape, or may respond to unmeasured variability such as the presence/absence of mangroves or perhaps to seascape structure outside the scale range included in this study.

The importance of a relatively fine scale structure $(<100 \mathrm{~m})$ for fish assemblages may relate to the preponderance of relatively small fish (mean $9.4 \mathrm{~cm} \mathrm{FL)}$ found using mangroves of SW Puerto Rico. In our study, the species with the finest scale response were also species with the largest proportion of small juveniles (Haemulon flavolineatum $<10 \mathrm{~cm}=90.8 \%$; Ocyurus chrysurus $<15 \mathrm{~cm}=88.9 \%$ ) of all focal species. Kramer \& Chapman (1999) found a strong positive linear allometric scaling relationship $\left(\mathrm{r}^{2}=0.73\right)$ between body size and home range size for 29 tropical marine fish, implying that, in general, smaller bodied fish sample their environment at finer spatial scales than do larger bodied fish. Alternatively, scale differences may be related to species-specific functional connectivity between inshore juvenile habitat and offshore adult habitat. Cocheret de la Morinière et al. (2002) proposed that Lutjanus griseus (as well as L. apodus and $H$. sciurus) are capable of long-distance, post-settlement, life-cycle migrations (PLCM) that connect inshore nursery habitats to adult habitats on offshore coral reefs. In contrast, in the same study, the authors differentiated $H$. flavolineatum and $O$. chrysurus as exhibiting a stepwise PLCM with multiple spatial shifts, with each sub-movement occurring at finer spatial scales than those in long distance PLCM species.

\section{Linking fish density and number of species to seascape types}

Across SW Puerto Rico, mangroves with extensive seagrass beds ( $>40 \%$ of the seascape) in close proximity $(<100 \mathrm{~m})$ supported higher mean fish density and number of species than mangroves with little or no seagrasses in close proximity. Elsewhere, several seascape ecology studies that have incorporated the distribution of surrounding habitat types have also found that the presence, amount and proximity of seagrasses has emerged as an important explanatory variable for fish spatial distributions in both mangroves (Pittman et al. 2004) and coral reefs (Kendall et al. 2003, Grober-Dunsmore 2007).

However, we also found that not all mangrove-seagrass combinations were used equally, with offshore mangrove-seagrass-dominated seascapes supporting higher mean assemblage density and higher Haemulon flavolineatum and Ocyurus chrysurus density than onshore mangroves with adjacent seagrasses. O. chrysurus was the most restricted in distribution, with only offshore mangroves in close proximity $(100 \mathrm{~m})$ to high coral reef (>15\%) and seagrass cover (>40\%) supporting high densities. Our results, therefore, indicate that the preference of $O$. chrysurus for mangroves and adjacent seagrasses is more specific than that indicated by Nagelkerken et al. (2002), and the assignment of equal ecological function to all mangrove-seagrassdominated seascapes across a region may be ecologically unrealistic.

A different spatial pattern of mangrove use was found for Lutjanus griseus, with higher densities in onshore mangroves. At the spatial extents examined in this study ( $\leq 600 \mathrm{~m}$ radial extents), the presence of coral reefs in close proximity to mangroves was not an important determinant of fish densities for L. griseus. Instead, higher densities of $L$. griseus were found in 
seascapes with extensive mangroves and extensive seagrasses, but not necessarily in close proximity to one another. A third response type was distinguished for Haemulon sciurus densities, which did not differ significantly between onshore or offshore mangroves and seagrasses, but exhibited lowest densities within onshore mangroves $>600 \mathrm{~m}$ from coral reefs.

The functional significance of close proximity of mangroves and seagrasses requires further investigation, although it is likely that useable resources, such as seagrasses in close proximity, will provide a higher quality habitat for many species than mangroves alone. This may result from a sensitive dependence on the requirement for seagrass as settlement substratum (Pollux et al. 2007), combined with the well-documented importance of seagrasses as feeding grounds for haemulids and lutjanids (Ogden \& Ehrlich 1977, Verweij et al. 2006). Furthermore, close proximity of highly structured habitat types may also provide an effective corridor that enhances survival during spatial transitions between habitat types (Dorenbosch et al. 2004).

Evidence now exists demonstrating that many early stage fish are capable of active habitat selection through well-developed sensory and locomotory functions (Leis \& McCormick 2002), and that behavioural preferences for settlement substratum may be mediated by the amount of substratum (McDermott \& Shima 2006). Yet virtually nothing is known about the process of hierarchical selection of habitat from region to seascape to individual patch. For example, larval or spawning adult fish may select patches suitable for settlement and spawning that are also surrounded by resources capable of supporting the sequence of developmental stages and post-settlement movements required to complete the life cycle. Further studies are required to elucidate on the complex functional interaction between seascape structure and the various ecological processes (settlement, predation, competition, growth rate, etc.) that determine fish species distribution patterns in nearshore marine environments. Furthermore, future seascape studies should investigate the influence of spatial and thematic resolution when using benthic habitat maps and may also usefully incorporate additional environmental variables at multiple scales, including substratum rugosity and the physical and chemical properties of the surrounding water.

\section{Implications for resource management}

The tendency to homogenise or subsume ecologically important habitat variability in order to increase operational effectiveness has serious implications for the way that we understand and manage our environment.
There is now an urgent need to understand the influence of seascape structure and to begin to incorporate seascape spatial patterning into resource management strategies. For instance, when designating management units such as critical habitat for multi-habitat users, it is important to look beyond individual habitat types toward identification of critical seascapes at scales appropriate to the movements of target species. However, the apparent diversity of the species-specific response to seascape structure, combined with a lack of information on which structural types form optimal habitat, highlight the need for a wider application of the multi-scale seascape approach, with the specific objective of informing management. With regard to environmental change, if seascape structure as a whole is important, then its functional integrity may change through the loss or gain of a single habitat type. Loss of seagrasses adjacent to mangroves may mean that mangroves can no longer be used by some species due to reduction of supplementary or complementary food resources, or of critical settlement substratum, or by disrupting the functional connectivity between mangroves and coral reefs. The results presented here are consistent with the recommendation for conservation efforts to protect seascapes with high connectivity between mangroves, seagrasses and coral reefs (Mumby et al. 2004). In addition, we add the caveat that a seascape type providing optimal function for one species may be sub-optimal for another species.

Acknowledgements. This research was supported by NOAA's Coral Reef Conservation Program. We thank the staff of the Biogeography Team at NOAA's Center for Coastal Monitoring and Assessment for field data collection; the Department of Marine Science at the University of Puerto Rico (Mayaguez) for field support; Captain Nazario for boat transportation whilst in Puerto Rico; and E. Finnen for GIS technical support. We also extend a massive thank you to K. M. Pittman and 4 anonymous reviewers for extensive comments that helped in the refinement of this manuscript.

\section{LITERATURE CITED}

Adams AJ, Dahlgren CP, Kellison GT, Kendall MS, Layman CA, Ley JA, Nagelkerken I, Serafy JE (2006) Nursery function of tropical back-reef systems. Mar Ecol Prog Ser 318:287-301

Addicott JF, Aho JM, Antolin MF, Padilla DK, Richardson JS, Soluk DA (1987) Ecological neighborhoods: scaling environmental patterns. Oikos 49:340-346

Beets J, Muehlstein L, Haught K, Schmitges H (2003) Habitat connectivity in coastal environments: patterns and movements of Caribbean coral reef fishes with emphasis on bluestriped grunt, Haemulon sciurus. Gulf Caribb Res 14(2):29-42

Blaber SJM (2000) Tropical estuarine fishes: ecology, exploitation, and conservation. Blackwell Science, London

Bohlke JE, Chaplin CCG (1993) Fishes of the Bahamas and adjacent tropical waters. University of Texas Press, Austin, TX 
Bouwmeester BLK (2005) Ontogenetic migration and growth of French grunt (Teleostei: Haemulon flavolineatum) as determined by coded wire tags. Masters thesis, University of Puerto Rico, Mayagüez

Brock VF (1954) A preliminary report on a method of estimating reef fish populations. J Wildl Manage 18:299-308

Christensen JD, Jeffrey CFG, Caldow C, Monaco ME, Kendall MS, Appeldoorn RS (2003) Cross-shelf habitat utilization patterns of reef fishes in southwestern Puerto Rico. Gulf Caribb Res 14(2):9-27

Clarke KR, Warwick RM (1994) Change in marine communities: an approach to statistical analyses and interpretation. Plymouth Marine Laboratory, Plymouth

Cocheret de la Morinière E, Pollux BJA, Nagelkerken I, van der Velde G (2002) Post-settlement life cycle migration patterns and habitat preference of coral reef fish that use seagrass and mangrove habitats as nurseries. Estuar Coast Shelf Sci 55:309-321

Dorenbosch M, van Riel MC, Nagelkerken I, van der Velde G (2004) The relationship of reef fish densities to the proximity of mangrove and seagrass nurseries. Estuar Coast Shelf Sci 60:37-48

Dunning JB, Danielson BJ, Pulliam HR (1992) Ecological processes that affect populations in complex landscapes. Oikos 65:169-175

Faunce CH, Serafy JE (2006) Mangroves as fish habitat: 50 years of field studies. Mar Ecol Prog Ser 318:1-18

García-Cagide AR, Claro R, Koshelev BV (1994) Reproducción. In: Claro R (ed) Ecología de los peces marinos de Cuba. Inst. Oceanol. Acad. Cienc. Cuba. and Cen. Invest. Quintana Roo (CIQRO) México, Chetumal, p 187-262

Grober-Dunsmore R, Frazer TK, Lindberg WJ, Beets J (2007) Reef fish and habitat relationships in Caribbean seascapes: the importance of reef context. Coral Reefs 26(1):210-216

Holland JD, Bert DG, Fahrig L (2004) Determining the spatial scale of species' response to habitat. BioScience 54:227-233

Kendall MS, Kruer CR, Buja KR, Christensen JD, Finkbeiner M, Warner R, Monaco ME (2002) Methods used to map the benthic habitats of Puerto Rico and the US Virgin Islands. NOAA Tech Mem 152. Silver Spring, MD

Kendall MS, Christensen JD, Hillis-Starr Z (2003) Multi-scale data used to analyze the spatial distribution of French grunts, Haemulon flavolineatum, relative to hard and soft bottom in a benthic landscape. Environ Biol Fish 66:19-26

Kramer DL, Chapman MR (1999) Implications of fish home range size and relocation for marine reserve function. Environ Biol Fish 55:65-79

Kruskal JB (1964) Nonmetric multidimensional scaling: a numerical method. Psychometrika 29:115-129

Leis JM, McCormick MI (2002) Recent developments in the biology, behaviour and ecology of the pelagic, larval stage of coral-reef fishes. In: Sale PF (ed) Coral reef fishes. Dynamics and diversity in a complex ecosystem. Academic Press, San Diego, CA

Lindholm J, Kaufman L, Miller S, Wagschal A, Newville M (2005) Movement of yellowtail snapper (Ocyurus chrysurus Block, 1790) and black grouper (Mycteroperca bonaci Poey, 1860) in the northern Florida Keys National Marine Sanctuary as determined by acoustic telemetry. Marine Sanctuaries Conservation Series MSD-05-4, US Department of Commerce, National Oceanic and Atmospheric Administration, Marine Sanctuaries Division, Silver Spring, MD

Editorial responsibility: Otto Kinne (Editor-in-Chief), Oldendorf/Luhe, Germany
Manson FJ, Loneragan NR, Harch BD, Skilleter GA, Williams L (2005) A broad-scale analysis of links between coastal fisheries production and mangrove extent: a case-study for northeastern Australia. Fish Res 74:69-85

McDermott CJ, Shima JS (2006) Ontogenetic shifts in microhabitat preference of the temperate reef fish Forsterygion lapillum: implications for population limitation. Mar Ecol Prog Ser 320:259-266

Moran PA (1950) Notes on continuous stochastic phenomena. Biometrika 37:17-23

Mumby PJ, Edwards AJ, Arias-Gonzalez JE, Lindeman KC and 8 others (2004) Mangroves enhance the biomass of coral reef fish communities in the Caribbean. Nature 427:533-536

Nagelkerken I, Dorenbosch M, Verberk WCEP, Cocheret de la Morinière E, van der Velde G (2000) Day-night shifts of fishes between shallow-water biotopes of a Caribbean bay, with emphasis on the nocturnal feeding of Haemulidae and Lutjanidae. Mar Ecol Prog Ser 194:55-64

Nagelkerken I, Roberts CM, van der Velde G, Dorenbosch M, van Riel MC, de la Morinière EC, Nienhuis PH (2002) How important are mangroves and seagrass beds for coral-reef fish? The nursery hypothesis tested on an island scale. Mar Ecol Prog Ser 244:299-305

Ogden JC, Ehrlich PR (1977) The behavior of heterotypic resting schools of juvenile grunts (Pomadasyidae). Mar Biol 42:273-280

Parrish JD (1989) Fish communities of interacting shallowwater habitats in tropical oceanic regions. Mar Ecol Prog Ser 58:143-160

Pittman SJ, McAlpine CA (2003) Movement of marine fish and decapod crustaceans: process, theory and application. Adv Mar Biol 44:205-294

Pittman SJ, McAlpine CA, Pittman KM (2004) Linking fish and prawns to their environment: a hierarchical landscape approach. Mar Ecol Prog Ser 283:233-254

Pollux BJA, Verberk WCEP, Dorenbosch M, Cocheret de la Morinière E, Nagelkerken I (2007) Habitat selection during settlement of three Caribbean coral reef fishes: indications for directed settlement to seagrass beds and mangroves. Limnol Oceanogr 52(2):903-907

Robbins BD, Bell SS (1994) Seagrass landscapes: a terrestrial approach to the marine environment. Trends Ecol Evol 9: 301-304

Rooker JR, Dennis GD (1991) Diel, lunar and seasonal changes in a mangrove fish assemblage off southwestern Puerto Rico. Bull Mar Sci 49:684-698

Sheaves M (2005) Nature and consequences of biological connectivity in mangrove systems. Mar Ecol Prog Ser 302: 293-305

Turner MG (1989) Landscape ecology: the effect of pattern on process. Annu Rev Ecol Syst 20:171-197

Verweij MC, Nagelkerken I, Wartenbergh SLJ, Pen IR, van der Velde G (2006) Caribbean mangroves and seagrass beds as daytime feeding habitats for juvenile French grunts, Haemulon flavolineatum. Mar Biol 149(6): 1291-1299

Watson M, Munro JL, Gell FR (2002) Settlement, movement and early juvenile mortality of the yellowtail snapper Ocyurus chrysurus. Mar Ecol Prog Ser 237:247-256

Wiens JA (1989) Spatial scaling in ecology. Funct Ecol 3: 385-397

Wiens JA, Stenseth NC, Van Horne B, Ims RA (1993) Ecological mechanisms and landscape ecology. Oikos 66: $369-380$

Submitted: December 5, 2006; Accepted: May 14, 2007

Proofs received from author(s): October 2, 2007 